\title{
Exégesis y teología. Una perspectiva desde la teología fundamental
}

\author{
Sergio Silva \\ FACULTAD DE TEOLOGÍA \\ PONTIFICIA UNIVERSIDAD CATÓLICA DE CHILE
}

En este artículo presento la relación que, a mi juicio, debe haber entre la exégesis y la teología sistemática, desde una perspectiva fundamental. En una primera sección expongo los fundamentos de la relación y hago una evaluación teológica del acercamiento histórico-crítico a la Escritura, que ha sido dominante en la exégesis y por lo tanto ha influido decisivamente en la teología sistemática. En la segunda sección presento la hermenéutica bíblica de Guardini, como un ejemplo atractivo de aproximación teológica a la Escritura. En una breve conclusión saco las consecuencias del camino recorrido.

\section{LOS FUNDAMENTOS DE LA RELACIÓN ENTRE EXÉGESIS Y TEOLOGÍA}

En mi opinión, la relación entre teología y exégesis hay que entenderla -y practicarla- sobre la base de dos tesis centrales, una de teología fundamental, la otra de hermenéutica.

a) Una tesis de teología fundamental

La fe cristiana es apostólica, lo que significa que depende de la comunidad apostólica, cuya fe es normativa para la Iglesia postapostólica.

La comunidad apostólica está constituida por aquellos hermanos y hermanas que -como se expresa Pedro- «han sido testigos de la resurrección» y «nos acompañaron [a los Doce] mientras vivía el Señor Jesús desde los tiempos en que Juan bautizaba hasta el día en que se lo llevaron al cielo» (Hch 1, 21-22). Según Pablo, esta comunidad habría estado constituida por «más de 500 hermanos» (1Co 15, 6).

Las comunidades fundadas por los miembros de la comunidad apostólica -que podemos llamar en plural las comunidades apostólicas para di- 
ferenciarlas de la comunidad apostólica recién descrita- necesitaron una norma objetiva para dirimir las cuestiones que fueron surgiendo acerca de la fe, y la encontraron en la Escritura del Antiguo y del Nuevo Testamento, porque reconocieron en sus escritos el kerygma recibido de viva voz de parte de la comunidad apostólica, y vivido por ella (aunque con las inevitables fallas humanas) ${ }^{1}$.

Es verdad que hay una diferencia insalvable entre la comunidad apostólica y las comunidades apostólicas, que consiste en que los miembros de la primera fueron testigos oculares de Jesús. Sin embargo, la diferencia no impide la continuidad fundamental de la fe. Por dos razones principales. La primera es que los miembros de ambas comunidades han recibido el Espíritu de Jesús resucitado, sin el cual no se puede creer en Jesús (ver 1Co 12, 3). La segunda es que la comunidad apostólica no creyó verdaderamente en Jesús hasta que no recibió el Espíritu, lo que devalúa en cierto modo el hecho de haber sido testigos oculares (ver, por ejemplo, Lc 24, 21; Hch 1, 6).

Podemos concluir con el Concilio, que recoge una tradición muy antigua, que la Escritura es «el alma de la sagrada teología» (DV 24). En efecto, la teología es intellectus fidei, esfuerzo por comprender la fe, cuya norma está en la Escritura. Si se trata de comprender la fe y su norma que es un escrito, entonces la teología tiene que plantearse, necesariamente, el tema hermenéutico.

b) Una tesis de hermenéutica

La tesis hermenéutica que propongo se inspira en los desarrollos de Gadamer y Ricoeur ${ }^{2}$. Ricoeur ha mostrado fehacientemente que un texto

1 Ver K. Rahner, Über die Schriftinspiration (Freiburg - Basel - Wien, 1958) (Quaestiones Disputatae 1). Traducción castellana: Inspiración de la Escritura (Barcelona 1970) (Quaestiones Disputatae 6).

2 H. G. Gadamer, Wahrheit und Methode. Grundzüge einer philosophischen Hermeneutik. 2. Auflage durch einen Nachtrag erweitert (Tübingen, J.C.B. Mohr [Paul Siebeck], 1965). Traducción castellana: Verdad y Método. Fundamentos de una hermenéutica filosófica (Salamanca 1977) (Hermeneia 7). De Paul Ricouer no es fácil señalar un texto suyo donde exponga de manera sucinta su teoría filosófica sobre la comprensión. Puede servir como una primera entrada el artículo «Herméneutique de l'idée de Révélation», en P. Ricoeur - E. Levinas - E. Haulotte - E. CornéLIS - C. Gefrré, La révélation (Bruxelles 1977) (Publications des Facultés Universitaires Saint-Louis 7), 15-54. Traducción castellana: «Hermenéutica de la idea de 
se independiza, adquiere autonomía, tanto de su autor como de su(s) destinatario(s) originario(s) y pasa a ser un objeto de comprensión para cualquier lector competente. En eso difiere de la palabra oral, que pertenece siempre a su emisor, que la puede retirar en cualquier momento del diálogo. La competencia del lector abarca varios niveles, desde el de la lengua en que está escrito el texto hasta el nivel de las ideas en él expresadas, pasando por el de los géneros literarios, el contexto histórico y cultural, etc. Al tener esta autonomía, el texto objetivo, es decir, tal como lo tenemos, tiene la prioridad en el proceso de su comprensión e interpretación.

Sin embargo, un texto, en su misma objetividad, presenta diversos aspectos, que pueden ser objeto de explicación científica. Antes de entrar a exponer estos aspectos, me parece necesario aclarar la distinción y la mutua referencia entre explicar científico y comprender hermenéutico cuando tienen como objeto un texto.

Por un lado, la diferencia. La ciencia, por definición, nunca puede captar la totalidad de su objeto porque lo capta desde un punto de vista particular -definido por sus axiomas, sus conceptos fundamentales, sus procedimientos de investigación, la tradición de la comunidad científica, etc.-, que corta la realidad bajo estudio según un plano particular, que dibuja en ese plano una figura que corresponde solo a un aspecto suyo $^{3}$. En un momento más mencionaré algunos aspectos del texto que, de hecho, han sido objeto de explicación científica. La comprensión hermenéutica, en cambio, intenta ayudar al intérprete a entrar en el mundo del texto para habitar en él, desplegando posibilidades suyas nuevas (Ricoeur). El «mundo del texto» no es el texto mismo, sino aquella realidad a la cual refiere mediante sus expresiones lingüísticas; dicho de otro modo, no es lo denotado por esas expresiones sino lo connotado por ellas. El lector es invitado por el texto a habitar en su mundo; para ello requiere del ejercicio de su imaginación, no solo de su razón. En la visión de Gadamer, la comprensión hace que el lector capte la verdad de la cosa (Sache) del texto, aplicándosela personalmente. Al hacer de la

revelación», en P. Ricoeur, Fe y Filosofía. Problemas del lenguaje religioso (Buenos Aires 1990), 159-198.

3 Esta idea la he desarrollado más en S. Silva G., ss.cc., «La inagotable realidad. Ciencia, Filosofía y Teología: mediaciones recíprocas», en Teología y Vida 33 (1992), 141-149. 
aplicación el momento clave de la comprensión, Gadamer se apoya en tres formas tradicionales de hermenéutica: la jurídica, la filológica y la teológica. La diferencia entre explicar y comprender se puede quizá resumir en que la primera intenta que un sujeto neutro y externo se apodere intelectualmente de un objeto puesto delante suyo, a distancia, mientras que la comprensión intenta -usando la analogía musical- que el intérprete o lector interprete el tema que le propone el texto, lo que implica un cierto grado de fusión con él, de apropiación personal del tema.

Por otro lado, entre explicación y comprensión hay mutua referencia. La explicación puede contribuir al proceso de comprensión cuando el lector la concibe como una ayuda para la «fusión de horizontes» que hace posible captar la verdad del texto aplicándosela a sí y su circunstancia (Gadamer), como una ayuda para entrar en el "mundo del texto» (Ricoeur). Pero puede también impedir la comprensión cuando erige sus resultados en la única explicación científica posible del texto, degradando a la comprensión hermenéutica a mera charlatanería. A su vez, ninguna explicación de un texto se puede hacer sin una comprensión mínima del texto, al menos sin comprender lo que dicen sus palabras y sus frases. Así, entre explicación y comprensión del texto hay una dialéctica de mutuo condicionamiento y enriquecimiento. Y no hay atajo que permita al lector comprender un texto sin la mediación de algún tipo de explicación, sea científica o no, sea consciente de ella o no, la use deliberadamente o no; ya el mero saber leer (o el comprender lo que se escucha) es una primera forma de explicación, en cierto modo espontánea, cuyo saber reflejo, científico, lo posee el gramático.

Volvamos al texto. Si dejamos de lado sus aspectos infraestructurales (alfabeto, papel, tinta, impresión, etc.) el texto en cuanto tal se presenta, entre otras cosas, como un producto histórico y cultural, un objeto lingüístico, el vehículo de un mensaje en un proceso de comunicación -mensaje que en ocasiones reviste la forma de un relato o narración-, una obra leída por diversos lectores en diversas circunstancias de la historia. Detengámonos un momento en estos diversos aspectos del texto.

1) El texto es un producto histórico y cultural. Todo texto es una obra humana, y por lo tanto está situado en un horizonte cultural histórico dado. Solo un texto que transmite pura información objetiva, sin nada propiamente humano, puede quedar fuera de esta afirmación, al menos 
en cuanto a su contenido, porque en cuanto al proceso de su producción es también una obra humana situada. Además de este horizonte del texto, en el proceso de comprensión está implicado el horizonte histórico y cultural del lector que lo interpreta, porque, como a toda obra humana, al texto se lo comprende desde el propio horizonte cultural histórico del intérprete. De ahí el primero de los dos momentos de la comprensión señalados por Gadamer: la «fusión de horizontes». Aquí tienen su lugar dos tipos de explicación, íntimamente vinculados entre sí: por un lado, la explicación histórico-crítica, que busca los referentes del tiempo en que la obra se escribió, la probable intención del autor, para reconstruir (siempre hipotéticamente) el horizonte histórico y cultural del texto, y, por otro, la explicación filológica, que busca determinar el significado de las palabras del texto en el tiempo en que fue escrito. En el caso de la Biblia, la exégesis histórico-crítica se ha centrado en la explicación de estos aspectos.

2) El texto es un «objeto lingüístico»y, en cuanto tal, está estructurado en diversos niveles: morfológico, sintáctico, semántico, porque las lenguas humanas presentan esos niveles estructurales.

De aquí al menos las siguientes explicaciones posibles (muchas veces necesarias para comprender): La explicación morfológica, necesaria sobre todo para comprender las lenguas (como el latín, por ejemplo) que tienen muchas declinaciones y complejas variantes. La explicación sintáctica, necesaria para esas lenguas complejas, pero también para ciertas épocas del castellano en que los autores buscaron revolver las palabras dentro de la frase. La explicación semántica, por ejemplo la que ha desarrollado desde hace un medio siglo A.J. Greimas, que descubre, partiendo de cuentos folclóricos, relatos terapéuticos y otros, una doble estructura en toda narración: una estructura estática y una estructura dinámica. La estructura estática está conformada por los 6 actuantes (Sujeto-Objeto, Destinador-Destinatario, Ayudante-Oponente). En la estructura dinámica, el Sujeto, enviado por el Destinador, pasa por una prueba calificadora; luego por una serie de pruebas principales en las que, ayudado por el Ayudante y dificultado por el Oponente, tiene que lograr realizar el Objeto; para terminar con una prueba glorificadora, que le permite ser reconocido; si logra superar todas estas pruebas, la situación inicial negativa será revertida en una situación positiva, para beneficio de los Destinatarios de su acción. 
3) El texto es un vehiculo portador de un mensaje en un proceso de comunicación. Aquí se sitúa la explicación retórica, que intenta sacar a luz qué contenidos quiere comunicar el texto (y, tras él, su autor) al lector y qué actitudes quiere producir en él; y a qué recurre para lograrlo: argumentos, golpes emocionales, etc.

4) En el caso de un texto narrativo, se ha desarrollado recientemente la explicación narrativa, que distingue entre historia y enunciación o entre qué se cuenta y cómo se cuenta ${ }^{4}$. De aquí que el análisis narrativo se interese en las diversas maneras en que los narradores pueden enunciar una misma cosa contada. Para el análisis narrativo el narrador narra desde un punto de vista y lo hace seleccionando los elementos de la historia en virtud de unos determinados intereses y disponiéndolos de una manera particular. Esto es así porque busca comunicar contenidos $y$ producir en el lector una serie de efectos o respuestas que integran tanto los diversos niveles de la actividad cognoscitiva humana como el complejo mundo emocional.

En segundo lugar, el narrador posee una estrategia al contar la historia, que busca introducir al lector en el mundo del relato. Sin el lector, el texto no está completo porque el acto de lectura es un juego estratégico de previsiones y anticipaciones. Así, el sentido de un texto se construye en una relación entre texto y lector. En virtud de la estrategia narrativa el lector no queda abandonado a un caos interpretativo, sino que es guiado por un cierto camino que el narrador astutamente puede balizar con señales más o menos explícitas.

Finalmente, en el mundo del texto construido por el narrador hay ciertas «reglas de verosimilitud» que pueden ser muy distintas a las reglas de credibilidad de los relatos historiográficos. Esto significa que el narrador construye un mundo coherente haciendo de la ficción un mundo semiaparte del mundo que el lector real experimenta normalmente, de manera que un signo significa cosas diferentes según sea la tela narrativa en la que se inserta.

5) Un texto es una obra leida a lo largo del tiempo por diversos lectores en diversas circunstancias personales y culturales; es, por lo tanto, una

\footnotetext{
Puede verse la ponencia de M. van Treek, "Acto de lectura y teología. Ensayo a propósito del lector en Génesis 1-3», en la Jornada de la Sociedad Chilena de Teología de 2009.
} 
obra interpretada diversamente. Aquí se sitúa la explicación que recoge la tradición interpretativa referida a un mismo texto o grupo de textos.

c) Una evaluación teológica de la exégesis histórico-crítica

La exégesis histórico-crítica ha sido en los últimos siglos la explicación científica dominante en los estudios bíblicos. La Pontificia Comisión Bíblica ha publicado un texto sobre la Interpretación de la Biblia en la Iglesia en 1993; en él define los métodos científicos de explicación de la Escritura como «un conjunto de procedimientos científicos puestos en acción para explicar los textos» ${ }^{5}$, y reconoce, además del método histórico-crítico, los nuevos métodos de análisis literario, entre los cuales señala el análisis retórico, el narrativo y el semiótico; afirma, finalmente, que todos estos métodos pueden ser valiosos en la medida en que aporten al conocimiento de los distintos aspectos del horizonte del texto bíblico ${ }^{6}$. Además de los métodos científicos, la Pontificia Comisión Bíblica acepta la legitimidad de diversos acercamientos a la Escritura; un acercamiento, dice, es «una búsqueda orientada según un punto de vista particular»; menciona tres acercamientos basados en la tradición -el acercamiento canónico, el recurso a las tradiciones judías de interpretación y el acercamiento que recoge la historia de los efectos del texto en sus lectores-, diversos acercamientos por las ciencias humanas -sociológico, de antropología cultural, sicológico y sicoanalítico- y el acercamiento contextual -nombra el liberacionista y el feminista-; termina la enumeración con una mención a la lectura fundamentalista, que rechaza decididamente ${ }^{8}$.

A mi entender, la exégesis histórico-crítica ha hecho un inapreciable aporte a la teología al hacernos tomar conciencia renovada, que ya nunca más deberíamos olvidar, del carácter histórico de la autocomunicación (revelación) de Dios.

Su riesgo ha sido creer que ella es la comprensión científica de la Escritura por antonomasia; al menos, creer que logra la comprensión científica del sentido histórico del texto, es decir, de lo que significó en

5 Pontificia Comisión Bíblica, La interpretación de la Biblia en la Iglesia (Santiago 1994) 31.

6 Pontificia Comisión Bíblica, La interpretación de la Biblia en la Iglesia, 32-46.

7 Pontificia Comisión Bíblica, La interpretación de la Biblia en la Iglesia, 31.

8 Pontificia Comisión Bíblica, La interpretación de la Biblia en la Iglesia, 47-68. 
el momento de su origen. Esta idea está tanto en el texto de la Pontificia Comisión Bíblica", por lo demás, tan positivo e interesante, como en el Jesús de Nazaret de Joseph Ratzinger (Benedicto XVI) ${ }^{10}$. Detrás de esta idea, me parece, está el supuesto hermenéutico erróneo de que el intérprete puede salirse completamente de su propio horizonte cultural histórico para entrar - por así decir en estado puro, sin su propio bagaje cultural- en el horizonte pasado del texto que interpreta.

Un riesgo más sutil, me parece, es pensar que, dado que la fe cristiana se basa en hechos históricos, la exégesis y la teología no pueden renunciar al método histórico-crítico, como si él tuviese el único acceso posible a los hechos ${ }^{11}$.

9 "Toda exégesis de los textos debe ser completada por una "hermenéutica" en el sentido reciente del término", es decir, que ayude a "franquear la distancia entre el tiempo de los autores y de los primeros destinatarios de los textos bíblicos, y nuestra época contemporánea», Pontificia Comisión Bíblica, La interpretación de la Biblia en la Iglesia, 71. Esta afirmación implica que la exégesis busca el sentido que tenían los textos en el tiempo de los autores y de los primeros destinatarios, y que la hermenéutica explora el sentido que pueden tener para nosotros hoy.

Luego de afirmar que el método histórico es imprescindible para la fe cristiana, porque ella se basa en hechos realmente acaecidos en la historia que culminan en la Encarnación, señala sus límites. "Para quien se siente hoy interpelado por la Biblia, el primer límite consiste en que, por su naturaleza, debe dejar la palabra en el pasado. En cuanto método histórico, busca los diversos hechos desde el contexto del tiempo en que se formaron los textos. Intenta conocer y entender con la mayor exactitud posible el pasado - tal como era en sí mismo- para descubrir así lo que el autor quiso y pudo decir en ese momento, considerando el contexto de su pensamiento y los acontecimientos de entonces. En la medida en que el método histórico es fiel a sí mismo, no solo debe estudiar la palabra como algo que pertenece al pasado, sino dejarla además en el pasado. Puede vislumbrar puntos de contacto con el presente, semejanzas con la actualidad; puede intentar encontrar aplicaciones para el presente, pero no puede hacerla actual, "de hoy", porque ello sobrepasaría lo que le es propio. Efectivamente, en la precisión de la explicación de lo que pasó reside tanto su fuerza como su limitación». Benedicto XVI, Jesús de Nazaret. Primera Parte: Desde el Bautismo a la Transfiguración (Santiago 2007) 12-13. En estas palabras el método histórico aparece como un observador absolutamente neutro, sin punto de vista particular, no contaminado por ningún presente.

11 De nuevo cito el Prólogo del Jesús de Nazaret de Joseph Ratzinger: «Hay que decir, ante todo, que el método histórico -precisamente por la naturaleza intrínseca de la teología y de la fe- es y sigue siendo una dimensión del trabajo exegético a la que no se puede renunciar. En efecto, para la fe bíblica es fundamental referirse a hechos históricos reales», Benedicto XVI, Jesús de Nazaret. Primera Parte: Desde el Bautismo a la Transfiguración, 11. 
El problema no es solo del método histórico-crítico. Los demás métodos científicos actuales de explicación también pueden convertirse en ideología, si pretenden ser una explicación total o, peor aun, si pretenden tener la llave única de acceso a la comprensión del sentido de la Escritura.

Dado que el horizonte de comprensión del intérprete es histórico y por lo tanto finito, cabe preguntarse si permite captar la verdad del texto, sobre todo cuando se trata de la Escritura que reconocemos inspirada. El aporte de Guardini en este punto me parece muy iluminador.

\section{LA HERMENÉUtica Bíblica DE GUARDini}

La hermenéutica bíblica de Romano Guardini (la expongo en el apartado "d» de esta sección) se basa en una hermenéutica general, es decir, en una teoría acerca de cómo conocemos la realidad (apartado «b»). Sus tesis acerca de cómo conocemos se sustentan a su vez en una idea de cómo es la realidad (tesis ontológica) y de cómo es el ser humano que conoce (tesis antropológica) (apartado «a») ${ }^{12}$. Guardini es consciente de que su visión de la hermenéutica va a contracorriente de la modernidad y se hace cargo de esta oposición (apartado «c»).

\section{a) Los supuestos}

La tesis ontológica afirma que la realidad no es homogénea, sino que se presenta como ordenada según grados que van de menor a mayor nivel o intensidad de ser, desde lo físico (inorgánico, muerto), pasando por lo vivo, lo síquico (caracterizado por la sensibilidad), hasta llegar a lo espiritual (que es el nivel propio de la persona humana). En cada uno de ellos hay diversas cualidades específicas.

12 Esta presentación se basa fundamentalmente en un texto clave de Guardini para su hermenéutica bíblica: «Sagrada Escritura y ciencia de la fe», en R. Guardini y otros, Biblia y ciencia de la fe. Edición, traducción e introducción de Carlos Granados y Agustín Giménez (Madrid 2007), 17-66 (Heilige Schrift und Glaubenswissenschaft [1928], en R. Guardini, Wurzeln eines grossen Lebenswerks. Aufsätze und kleine Schriften, Band II, 337-383 (Mainz 2001). Las ideas de Guardini sobre el conocimiento están fuertemente influidas por la filosofía fenomenológica de Max Scheler. Ver J. Reger, Die Phänomenologie als theologisches Erkenntnisprinzip. R. GUARDINI - M. SCHELER. St. Ottilien, EOS Verlag, 1999 (Dissertationen. Theologische Reihe 82). 
La tesis antropológica dice que el ser humano es microcosmos, es decir, tiene en sí todos y cada uno de estos diversos niveles de ser de la realidad.

b) Algunas tesis de hermenéutica general

Para Guardini, conocer no es mero registrar, al modo como funciona una cámara fotográfica, sino apropiarse del objeto. Esto implica que el objeto conocido activa algo en la interioridad del sujeto que lo conoce, que hasta ahora no se había activado. Así, el conocimiento nuevo transforma al sujeto, porque se autorrealiza de una manera nueva; esta transformación será de mayor o menor riqueza, según sea el nivel de ser de lo que ha conocido y la intensidad con que el sujeto se lo ha apropiado.

Por eso es clave que el sujeto se sitúe expresa y deliberadamente en el nivel de realidad del objeto y, en ese nivel, en el de su cualidad específica. Esto implica que a la diversidad óntica de las cosas corresponde en el sujeto que conoce una diversidad noética, es decir, de actitud de conocimiento, de apertura a la realidad por conocer.

De aquí le viene al conocimiento su dimensión ética, en el sentido que la realidad que se da a conocer exige del sujeto una determinada apertura a ella; si esta no se da, el conocimiento pierde legitimidad y riqueza. Dicho de otro modo, el sujeto debe tomar en serio al objeto. De aquí también la dimensión pedagógica del conocimiento, porque hay que educar y educarse para reconocer adecuadamente estas diferencias en el nivel de ser de la realidad y para acomodarse noéticamente a ellas. De aquí, también, las posibles perturbaciones y distorsiones del conocimiento.

Para Guardini es fundamental tomar conciencia de que lo universal (que se expresa en los conceptos) no agota lo concreto de cada cosa; el conocimiento es un acto vivo concreto que capta lo universal como presente en esta cosa concreta.

Finalmente, cuando hay conflictos entre conocimientos verdaderos, hay que buscar aquel nivel superior desde el cual pueda verse la unidad entre ambos. En esta propuesta se percibe con claridad la que idea -que Guardini ha expuesto ampliamente en su único libro propiamente filosófico ${ }^{13}$ - de que la realidad concreta está constituida por pares de polos

13 R. Guardini, Der Gegensatz. Versuche zu einer Philosophie des Lebendig-Konkreten (Mainz ${ }^{2}$ 1998). 
opuestos en tensión, de manera que tanto el conocimiento de la realidad como la acción deben respetar esa tensión, sin intentar romperla a favor de uno de los polos.

c) El problema de la modernidad y su posible superación

Esta concepción del conocimiento y de la realidad pone a Guardini en abierta contradicción con las ideas dominantes en la modernidad. Él es plenamente consciente de esta contradicción. De hecho, afirma que la modernidad desconoció la diversidad óntica y la correspondiente diversidad noética, porque erigió como único modo de conocimiento válido, es decir, científico, el de la Física. Por eso, la ciencia moderna ha tratado de comprender lo vivo como si fuera inorgánico; $y$, cuando ha aceptado que existen niveles superiores al del mundo inorgánico de la materia, ha intentado comprender lo síquico como si fuera biológico, y lo espiritual como si fuera síquico. Es decir, ha intentado reducir los niveles superiores a los inferiores.

Pero Guardini no se contenta con contradecir, también quiere aportar a la superación de lo que le parece mal en la modernidad. Uno de los caminos que propone es una consideración de la obra de arte. En una conferencia en la Academia de Bellas Artes de Stuttgart en 1947, Guardini expone su idea acerca de «la esencia de la obra de arte» ${ }^{14}$. Me parece notable que adelante en ella ideas hermenéuticas que desarrollará 30 años después Paul Ricoeur, como el mundo del texto, el hombre capaz, y también la dimensión escatológica de la comprensión, que acentuará Gadamer. Presento las ideas principales de esta conferencia.

El artista trabaja las formas "para potenciar la capacidad de expresión que tienen y permitir que llegue a ser lo auténtico»" ${ }^{15}$. Es lo que los antiguos llamaban la mimesis, la imitación de la naturaleza, expresión no muy feliz, porque hace pensar en realismo y verismo. Pero que hay que comprender más profundamente, según el modelo de «la relación en que está el actor con la figura que ha creado el dramaturgo» ${ }^{16}$; así la mimesis refiere a ese acto mediante el cual el artista pone toda su capacidad a

14 R. Guardini, «Das Wesen des Kunstwerks», en R. Guardini, Wurzeln eines grossen Lebenswerks. Aufsätze und kleine Schriften, Band III, 337-383 (Mainz 2002). Las citas textuales en el texto son traducción mía.

15 R. Guardini, «Das Wesen des Kunstwerks», 338.

16 R. Guardini, «Das Wesen des Kunstwerks», 338. 
disposición de la esencia y la logra representar. Es lo que hace también la naturaleza, pero el artista lo hace mejor aún, en la medida en que el ser humano está por encima de la naturaleza.

Junto con captar la esencia de la cosa que representa en su obra, el artista se capta a sí mismo, porque "al sentir el contacto con el ser de la cosa, algo se despierta en su propio ser" ${ }^{17}$. De ahí que el ser humano pueda ser llamado aquel ser "que es capaz de responder a las cosas del mundo con su ser interior y, en esa respuesta, [es capaz] de realizarse a sí mismo» ${ }^{18}$.

Los distintos ámbitos del arte son muy diversos, «pero en último término buscan lo mismo: dar una expresión a la unidad del ser del mundo y del hombre, expresión que esa unidad no tiene en la realidad; y, en esa expresión, hacer resonar la totalidad de la existencia» (Dasein) ${ }^{19}$.

Si llamamos primer mundo al mundo de la naturaleza y segundo mundo al que surge del encuentro del hombre con ella, la obra de arte no pertenece al primero, sino al segundo, y en él tiene un puesto especial: la obra de arte, aunque esté muy condicionada y sea muy limitada, «tiene un carácter de plenitud y de totalidad que la capacita para ser símbolo de la existencia misma, del universo ${ }^{20}$. Toda obra de arte es «mundana, es un espacio al que se le ha dado forma y se ha llenado de contenidos de sentido, un espacio en el que se puede entrar mirando, oyendo, moviéndose. Este espacio está construido de manera diferente al de la realidad inmediata $»^{21}$. Tiene una cualidad propia: «la cosa y el ser humano están en él abiertos. En el espacio de la existencia cotidiana la cosa y el ser humano están vinculados y ocultos. Lo que de ellos se puede percibir expresa a la vez que esconde su esencia. El acto del artista, que ve y representa la esencia, la logra expresar más plenamente. Lo interior está ahora también "fuera", se ha hecho fenómeno y puede ser contemplado; lo exterior está ahora también "dentro", es sentido y vivenciado y puede ser acogido en la propia vivencia. Pero, precisamente por este acontecimiento, la unidad se hace poderosa, la totalidad se hace presente

17 R. Guardini, «Das Wesen des Kunstwerks», 338.

18 R. Guardini, «Das Wesen des Kunstwerks», 339.

19 R. Guardini, «Das Wesen des Kunstwerks», 347.

20 R. Guardini, «Das Wesen des Kunstwerks», 349.

21 R. Guardini, «Das Wesen des Kunstwerks», 349. 
y se la puede sentir $\nu^{22}$. Se ha superado la separación: las cosas entre sí y el hombre con ellas están en una cercanía que no se da en el mundo inmediato. "Por eso, el que contempla la obra de arte, en la medida en que entra en su mundo y lo hace suyo, puede vivir en la totalidad $»^{23}$.

De aquí que para captar la obra de arte no se exige solo ver y oír, tampoco un mero gozar. "La obra de arte ante todo abre un espacio en el que el ser humano puede entrar, en el que puede respirar, moverse y entrar en contacto con las cosas y los hombres que han quedado patentes ${ }^{24}$. Pero para ello debe esforzarse; de aquí la hoy urgentísima tarea de la contemplación, porque «nos hemos convertido en activistas y estamos orgullosos de ello, cuando en realidad hemos perdido la práctica de hacer silencio, recogernos, abrirnos, contemplar y acoger en nosotros las esencias ${ }^{25}$. Por eso pocos tienen hoy la relación adecuada con la obra de arte, que consiste en "callar, recogerse, entrar, mirar y escuchar atentamente con el sentido despierto, participar ${ }^{26}$. Solo así se nos abre el mundo de la obra. Y en este espacio de la obra de arte el que la contempla experimenta que «algo le pasa a él mismo: cambia de estado. El cerco apretado que rodea su ser se suelta, más o menos según cuán profundamente entre en la obra de arte, cuán vitalmente la comprenda, cuán de cerca le concierna. Él se vuelve más claro para sí mismo; no mediante una reflexión teórica, sino en el sentido de una iluminación inmediata. El peso de lo no experimentado de su propio presente se hace más ligero. Se hace más profundamente consciente de la posibilidad de ser auténtico, puro, pleno, transformado $»^{27}$.

La obra de arte, aunque ajena al mundo real, está involucrada de alguna manera en él. Porque «surge del anhelo de esa existencia plena que no existe, pero que el ser humano, a pesar de todos los desengaños, cree que debe llegar a darse; esa existencia en la que el ente ha alcanzado su plena verdad y la realidad ha quedado sometida a las esencias; donde las cosas están en la interioridad del corazón que se ha abierto y el corazón

\footnotetext{
R. Guardini, «Das Wesen des Kunstwerks», 349.

R. Guardini, «Das Wesen des Kunstwerks», 350.

24 R. Guardini, «Das Wesen des Kunstwerks», 350.

25 R. Guardini, «Das Wesen des Kunstwerks», 350.

26 R. Guardini, «Das Wesen des Kunstwerks», 350.

27 R. Guardini, «Das Wesen des Kunstwerks», 350.
} 
habla a través de la variedad de las cosas $»^{28}$. Por eso, «el arte despliega anticipadamente algo que aún no existe. No puede decir cómo se llegará a ello; sin embargo, da una seguridad misteriosamente consoladora de que llegará a ser $\aleph^{29}$ : la promesa de que así será se siente en lo más hondo de la propia interioridad.

En último término, la obra de arte recibe su sentido auténtico de Dios. «La revelación habla del surgimiento del mundo nuevo a partir de la destrucción y el juicio» ${ }^{30}$; lo que no es posible a partir del mundo natural. Sabemos que "las cosas no son lo que deberían ser, pero no podemos mediante ninguna ciencia ni técnica hacerlas ser, a partir de sí mismas, lo que deberían ser $»^{31}$. La existencia no da por sí misma aquello que se busca. El auténtico adviento debe realmente advenir a nosotros desde Dios, como el cielo nuevo y la tierra nueva. «El arte habla de esto nuevo, a menudo sin saber de qué está hablando» ${ }^{32}$.

De aquí le viene a la obra de arte su carácter religioso y «no por contenidos inmediatamente religiosos $»^{33}$, sino por algo que está «en la estructura misma de la obra de arte en cuanto tal: en su apuntar al adviento, a aquel adviento en cuanto tal, que ya no se puede fundar a partir del mundo. Toda auténtica obra de arte es por su esencia "escatológica" y remite al mundo, por encima de sí mismo, a algo que viene» ${ }^{34}$. De ahí que también la relación auténtica a una obra de arte desemboca en algo religioso. Lo anterior ha mostrado que «no le hago justicia a una obra de arte cuando solo la "gozo", sino cuando hago mío el encuentro del creador con la cosa, porque entonces entro en el espacio que surge de la obra de arte y vivo en ese mundo más puro que ella crea. A medida que lo contemplo, ese mundo se apodera de mí; en mí mismo es convocado "lo mejor" y es liberado de las ataduras y de la presión en que lo tiene sujeto la existencia cotidiana. Por lo mismo, en esa contemplación barrunto lo que soy auténticamente y experimento la promesa de que algún día voy

\footnotetext{
28 R. Guardini, «Das Wesen des Kunstwerks», 357.

29 R. Guardini, «Das Wesen des Kunstwerks», 357.

30 R. Guardini, «Das Wesen des Kunstwerks», 357.

31 R. Guardini, «Das Wesen des Kunstwerks», 358.

32 R. Guardini, «Das Wesen des Kunstwerks», 358.

33 R. Guardini, «Das Wesen des Kunstwerks», 358.

34 R. Guardini, «Das Wesen des Kunstwerks», 358.
} 
a poder alcanzarlo. Dicho más exactamente: algún día, en el adviento final, cuando lo auténtico del mundo advenga a él, vendrá también a mi encuentro mi auténtico ser y se me hará propio»" ${ }^{35}$.

d) Las tesis fundamentales de hermenéutica bíblica

Termino esta sección reseñando muy brevemente las tesis fundamentales de la hermenéutica bíblica de Guardini. Su punto de partida es que el Nuevo Testamento - pero esta afirmación vale para toda la Escritura- no es un texto literario o religioso cualquiera, porque es expresión de una revelación, aunque de hecho esta se presente encarnada en un relato humano históricamente condicionado, lo que puede provocar un conflicto que dificulte la interpretación. Se da aquí, entonces, una polaridad, que el intérprete debe respetar, entre la revelación divina y su expresión literaria humana.

Una primera consecuencia es que la actitud cognoscitiva adecuada ante el texto bíblico es la fe, no cabe una objetividad no participante. Y aunque la fe es don, ella activa, pone en acto, lo más propio del ser humano, que, por lo tanto, consciente o inconscientemente, aspira a ella, la espera desde lo más hondo de su ser. Además, la fe se expresa en actos humanos, que el creyente debe justificar ante los criterios humanos de valor.

Por otro lado, debido a que la revelación se da encarnada en textos humanos, el conocimiento de fe no suprime ni deja de lado los otros conocimientos, sino que se los subordina jerarquizada y analógicamente. Aunque en este texto programático que he estado presentando, Guardini no se detiene en analizar cómo se hace en concreto esta subordinación, en los muchos escritos que dedicó a explicar y comprender textos de la Escritura recurre a gran variedad de conocimientos simplemente humanos. Pongo un ejemplo, tomado de su estudio de la figura de Cristo en los escritos paulinos y joánicos. Cuando trata acerca del Apocalipsis, Guardini se pregunta cómo comprender las visiones que se relatan en él. Descarta explicaciones posibles que se han dado. Por ejemplo, afirmar que se trata de alegorías, le parece racionalismo, que desconoce que se trata de imágenes, y estas no requieren ser pensadas, sino vistas, contempladas. Rechaza también el esfuerzo por reducir el significado de las

35 R. Guardini, «Das Wesen des Kunstwerks», 358-359. 
imágenes presentes en las visiones a sus posibles orígenes históricos; por ejemplo, la visión que dice que las copas con incienso son las oraciones de los santos se explicaría por asociación con el culto en que el humo del incienso asciende hacia Dios; pero este tipo de explicación solo dice de dónde viene el material presente en la visión, no dice cómo ese material se estructura en ella ni cómo debe ser comprendido. Un poco más se acerca, a su entender, el intento de comprenderlas como fábulas, pero estas son narraciones, no visión de imágenes. Finalmente, se le abre el camino de los sueños, porque en ellos las cosas que se presentan no solo se afirman o narran, sino que se realizan; en el sueño reina el inconsciente, que deja fuera de juego tanto al pensamiento crítico de la vigilia como a la voluntad dominadora; y lo que aparece en el sueño no significa solamente algo, sino que lo es. Sin embargo, Guardini es fiel a sus principios hermenéuticos, porque identificar las visiones del Apocalipsis con nuestros sueños implicaría reducirlas a un nivel inferior: la revelación sería comprendida como un acontecimiento meramente humano. Los sueños solo le han abierto un acceso posible a la comprensión de las visiones, ahora deben retirarse; las visiones tienen estructuras anímicas semejantes a las del sueño, pero tienen un origen diverso, profético, son fruto del Espíritu de Dios ${ }^{36}$.

\section{3. ¿QUÉ CONCLUIR?}

En primer lugar, para el teólogo vale el axioma que hemos recordado al inicio: "La Escritura es el alma de la teología», porque ella es, para siempre, la norma de la fe cristiana. Ahora bien, la Escritura es Palabra de Dios encarnada en palabra humana, por lo que queda entregada a los complejos procesos humanos de comprensión.

En teología, lo decisivo es comprender el texto de la Escritura tal como lo tenemos ${ }^{37}$, porque es el que nos ha transmitido la comunidad apostólica; y se trata de comprenderlo sin reducir la comprensión a la sola palabra humana de los textos escriturísticos, pero a la vez sin saltarse esa comprensión.

36 Ver R. Guardini, Das Christusbild der paulinischen und johanneischen Schriften (Mainz 1987), 209-215.

37 Es un texto que tiene que ser revisado críticamente $-y$, en cierto sentido, reconstruido- a la luz de los criterios de la crítica textual, porque no tenemos los originales firmados por sus autores. 
La comprensión de la Escritura se ve facilitada y enriquecida con los diversos métodos científicos de explicación de la palabra humana de su texto y con los diversos acercamientos a ella. Todos estos métodos y acercamientos están marcados por la historicidad propia de todo lo humano, de modo que podemos afirmar que, así como hubo un tiempo pasado en que aún no existían, es muy probable que habrá un tiempo futuro en que dejarán de existir. Por lo tanto, ninguno de estos métodos y acercamientos puede erigirse en un absoluto. En cada momento, diversos teólogos dialogarán con diversas explicaciones, lo que contribuirá a una legítima pluralidad teológica, quizá difícil de controlar centralmente e imposible de sintetizar, que es reflejo de nuestra insuperable finitud.

Los exégetas, sea cual sea el método y acercamiento que emplean, trabajan el texto bíblico desde su propio horizonte histórico y cultural, siempre particular, siempre limitado, de manera que, quieran o no, su trabajo exegético es una interpretación del texto, no es nunca una pura explicación científica de él. Por eso, hacen bien en acoger e integrar la afirmación teológica sobre el carácter inspirado de la Escritura, para no encerrar su interpretación en los límites que permiten las coordenadas puramente humanas de su método científico, para dejarla abierta a un posible sentido mayor.

Tanto la teología como la hermenéutica son esfuerzos por comprender un texto. En ambos casos se trabaja con el supuesto de que el texto se halla trascendido en las tres direcciones del tiempo. En la dirección del pasado, porque se reconoce que el texto tiene un origen anterior, situado en un horizonte histórico y cultural distinto del actual; en el caso de la teología, este horizonte remonta, verticalmente, hacia Dios mismo, que ha inspirado la Escritura en los diversos tiempos del origen humano de sus textos. En la dirección del futuro, el texto está trascendido por el carácter escatológico que es propio tanto de la Palabra de Dios -que ha de crear un cielo nuevo y una tierra nueva al fin de los tiempos- como de la hermenéutica, que reconoce que la verdad de un texto se va desplegando en la historia de los efectos que produce en sus lectores. Y en la dirección del presente, finalmente, porque la hermenéutica reconoce que la comprensión solo se logra por apropiación personal del texto, es decir, con Gadamer, por la aplicación que hace el lector de la verdad a la que apunta el texto a su propia vida, o bien, con Ricoeur, porque el lector habita el mundo del texto y despliega en él sus mejores potencialidades 
humanas; y porque para la teología, y para la fe antes que ella, la verdad de la Escritura se hace, en obediencia a Dios, con la libertad de hijos, de manera que la vida de la fe de las comunidades y particularmente de los santos -canonizados oficialmente o no- es también realización viva de la Escritura y, por ello, contribuye de manera insuperable a su interpretación.

Resumen: El artículo presenta la relación entre la exégesis y la teología sistemática desde una perspectiva fundamental. La primera sección expone los fundamentos de la relación, sobre la base de dos tesis. La primera es de teología fundamental: la fe cristiana es "apostólica", lo que significa que depende de la comunidad apostólica, cuya fe es normativa para la Iglesia postapostólica, y esta fe fue "objetivada" en la Escritura que esa comunidad legó a la Iglesia postapostólica. La segunda tesis es de hermenéutica, inspirada en la filosofía de Gadamer y Ricoeur, y subraya a la vez la distinción y la mutua referencia entre los procesos de explicación científica y de comprensión hermenéutica cuando tienen como objeto un texto. Luego se hace una evaluación teológica del acercamiento histórico-crítico a la Escritura, que ha sido la explicación científica dominante en la exégesis y por lo tanto ha influido decisivamente en la teología sistemática. La segunda sección presenta la hermenéutica bíblica de Guardini, como un ejemplo atractivo de aproximación teológica a la Escritura. La conclusión saca las consecuencias del camino recorrido.

Palabras clave: Norma de la fe, Escritura, explicación científica, comprensión hermenéutica, Romano Guardini, pluralismo de métodos.

Abstract: The article presents the relationship between exegesis and systematic theology from a fundamental perspective. The first section discusses the fundamentals of the relationship based on two theses. The first pertains to fundamental theology: Christian faith is "apostolic", meaning it depends on the apostolic community, whose faith is normative for the post-apostolic Church. This faith was "objectified" in the Scripture bequeathed by such community to the post-apostolic church. The second thesis pertains to hermeneutics, inspired by the philosophy of Gadamer and Ricoeur. It emphasizes both the distinction and mutual reference between the processes of scientific explanation and of hermeneutic understanding when their object is a text. Then, a theological evaluation of the historical-critical approach to the Scripture is presented, which has been the dominant scientific explanation in exegesis and therefore has decisively influenced systematic theology. The second section presents Guardini's biblical hermeneutics as an attractive example of a theological approach to the Scripture. The conclusion draws the consequences of the travelled path.

Keywords: Norm of faith, Scripture, scientific explanation, hermeneutic understanding, Romano Guardini, pluralism of methods. 